\title{
A IMPORTÂNCIA HISTÓRICO-CULTURAL DOS IMIGRANTES NIKKEIS NO BRASIL
}

Shuhei Hosokawa

No período de 1908 a 1960 , cerca de 250.000 japoneses imigraram ao Brasil e aqui permaneceram, apresentando elevado índice de fixação. $\mathrm{E}$, atualmente, incluindo-se seus descendentes, a população dos nikkeis expandiu-se, sendo estimado em torno de 1,5 milhões. Este ano, por completar cem anos após o início desse movimento migratório, a mídia do Brasil e do Japão tem destacado esse fato histórico. O choque cultural dos primeiros imigrantes, a história de incentivos e proibições da relação político-econômica entre os dois países, a contribuição à agricultura e indústria, a ascensão social dos nisseis e sanseis, $o$ fenômeno recente decasségui ${ }^{1}$, a propagação da culinária japonesa e do mangá no Brasil e o seu reverso, a aceitação calorosa de capoeira, futebol e samba por parte dos japoneses, muitos foram os temas citados e comentados no ano do centenário. Neste trabalho, pretendo revisitar os cem anos da imigração, como exemplo concreto de contato cultural, com contornos interessantes.

A imigração constituiu uma parte importante da história japonesa moderna e, nesse sentido, a pesquisa sobre a cultura da imigração nipônica não é nada mais do que um aspecto da pesquisa sobre a cultura japonesa. Assim como não se pode contar a história do Brasil - país dos imigrantes - deixando de lado o processo migratório, desconsiderar a história da migração no contexto da história japonesa seria o mesmo que contar uma história parcial, com lacunas. Pode-se afirmar que o montante dos emigrantes significou uma parcela muito reduzida da população japonesa, mas não é possível compreender a 
modernização japonesa sem considerar esse fator. Entretanto, esses emigrantes têm sido ignorados pelos livros didáticos de história do Japão. Acredito que deva ser redigida uma História Moderna Japonesa que contemple os imigrantes japoneses e seus descendentes. Neste trabalho, pretendo apresentar alguns pontos importantes para se pensar sobre a história e a cultura da imigração japonesa no Brasil.

\section{Os japoneses que emigraram para o Novo Continente}

Nos meados do século XIX, devido à abertura dos portos, o Japão foi levado a se inserir na conjuntura político-econômica mundial, mais do que na fase anterior. É tese corrente que para o Japão se tornar uma potência e se igualar às demais nações desenvolvidas, no turbilhão do imperialismo reinante, o governo japonês teve que tomar medidas urgentes e, nesse processo, acabou tendo que enfrentar os mesmos problemas que os dos países europeus, gerando como subproduto uma multidão de emigrantes, em escala superior do que verificada nas migrações populacionais de outrora. $\mathrm{O}$ grau de desenvolvimento da economia metropolitana, a evasão da população rural, a limitação no desbravamento de terras para o cultivo, além da recessão, colheita baixa e desemprego, foram os fatores de expulsão de trabalhadores para o mercado de trabalho no exterior. Outros fatores, como repressão religiosa e política, embora em menor escala, também contribuíram para a evasão. Do outro lado, os paises do Novo Continente necessitavam de mão-de-obra para o desenvolvimento, principalmente na agricultura e indústria. Nesse contexto, é possível afirmar que um traço marcante da emigração japonesa é o fato de poder identificar, entre os emigrantes da fase anterior à guerra, grande quantidade de segundo e terceiro filhos, justamente porque, de acordo com o Código Civil da era Meiji, não tinham direito à herança.

No caso da emigração ao Brasil, a partida do navio Kasato-maru foi consequência, por um lado, da necessidade do Japão de encontrar um país receptor de emigrantes alternativo à América do Norte, e, por outro, da crise econômica, fruto da Guerra JapãoRussia. No Brasil, a permissão oficial da imigração japonesa foi possível na media em que os cafeicultores paulistas, favoráveis à introdução da força de trabalho alternativa ao trabalho escravo, conseguiram vencer a disputa com o setor diplomático, cuja opinião era favorável à proibição, baseando-se no temor da "praga amarela". No contexto da história brasileira, esse período pode ser considerado como fase de deslocamento do centro de produção agrícola e industrial do país, das áreas desenvolvidas a partir do período colonial para o Estado de São Paulo e sul do país. A modernização da administração das fazendas, impulsionada a partir da abolição da escravatura (1888), exigia a introdução de nova força de trabalho, no caso os imigrantes japoneses. Como pode se constatar, os primeiros imigrantes foram condicionados pela concepção da imigração como fonte de força de trabalho e também 
pelo mercado de café. Nesse sentido, nada mudou se comparado com as circunstâncias do trabalhador decasségui que parte para o Japão.

\section{Características da imigração japonesa no Brasil}

Neste tópico, verificaremos as características da comunidade de descendentes japoneses no Brasil em comparação com outras comunidades similares de outros países. Em primeiro lugar, é possível apontar para a continuidade do movimento e grande escala do ponto de vista demográfico. A imigração japonesa à América do Norte concentrou-se no período que abrange o final do século XIX à década de 20 do século seguinte, e após a interrupção, ocorrida em 1924, ficou restrita à pequena escala, de forma esporádica. $\mathrm{Na}$ América do Sul, o Peru começou a receber os imigrantes japoneses dez anos antes do Brasil, mas devido ao forte sentimento antinipônico, como verificado durante a Segunda Guerra, em que vários nipônicos foram extraditados para a América do Norte na condição de povo inimigo, não teve forte movimento para atrair novos imigrantes no pós-guerra. Nos países como Bolívia, Paraguai e Argentina, há registros da presença de japoneses na fase anterior à guerra, sem que tenha ocorrido, no entanto, uma imigração planejada em larga escala. Em contraposição a esses casos, a onda imigratória ao Brasil teve início nos primeiros anos do século XX e se estendeu até a década de 60 , com interrupção somente no período da Guerra. Para ilustrar, a existência de jornais e de revistas literárias da comunidade, publicados em japonês e que têm como público-alvo principal os imigrantes, é um fenômeno provavelmente verificado apenas no Brasil. Isto se deve, em grande parte, à entrada contínua de imigrantes japoneses no Brasil, na fase pós-guerra.

Em segundo lugar, destaca-se a grande proporção dos imigrantes permanentes entre os japoneses residentes no Brasil, que fica bastante evidente em comparação com o caso norte-americano. Entre as décadas de 60 e 70 do século passado, quando ocorreu um grande aporte das empresas japonesas no Brasil, havia muitos nativos enviados pelas matrizes, mas não se comparava com o contingente que já estava presente e que formava uma comunidade com meio século de história. Em contraposição, na América do Norte, mesmo após o término da imigração nos anos 20, os japoneses de matizes diversos, como funcionários de empresas e órgãos governamentais, estudantes, turistas e artistas etc., permaneceram por curto ou longo período, como temporário ou em definitivo, fazendo com que, na comparação com o Brasil, os imigrantes e seus descendentes ocupem uma parcela reduzida da comunidade nipônica. Não se pode menosprezar a atuação desses imigrantes como portadores da cultura japonesa, mas sua importância é relativa. Em contraposição à realidade norte-americana, no Brasil, o número de white collar workers, "empregados de escritório" estudantes e turistas que permanecem no país, seja por curto ou longo período, é relativamente reduzido, e a 
importância dos imigrantes pode ser verificada tanto do ponto de vista demográfico quanto da atuação cultural. Por exemplo, as matrizes das principais agências de viagens do Japão, que têm como destino principal o Brasil, estão em São Paulo (fato semelhante ocorre também no Peru e na Bolívia). Certamente o percentual das agências de turismo que operam na rota Japão-EUA, administradas pelos japoneses e seus descendentes, não deve ser tão alta. É necessário averiguar a questão em maiores detalhes, mas esse fato deve ter relação com a história das agências nikkeis que cresceram a partir dos anos 50, tendo como clientes os grupos de japoneses residentes no Brasil que visitavam o Japão.

Como terceiro ponto, destaca-se o fato de o português ser a língua falada no Brasil. No Japão, o número de aprendizes de português é radicalmente inferior àqueles de inglês, exigindo-se o serviço dos intérpretes nas situações de contato (turismo, transação comercial, conferências etc.), mas, pelo menos por ora, a maior parte dos falantes de japonês do Brasil é oriunda da comunidade japonesa. Como contraponto, há uma impressão de que, na América do Norte, o percentual dos descendentes de japoneses entre os aprendizes de língua japonesa e pesquisadores já não é tão alto. Nesse continente, a língua japonesa deixou de ser usada no lar há muito tempo e é fraca a motivação de estudá-la por ser um descendente, assim como não há expectativa por parte da sociedade no sentido de que o indivíduo domine o japonês por ser um nikkei. Como se verifica, este fator lingüístico também está relacionado à importante presença da comunidade japonesa, no contexto da história do intercâmbio entre o Brasil e o Japão. A relação duradoura do ponto de vista político, econômico, industrial e cultural entre o Japão e a América do Norte se aprofundou extrapolando a comunidade japonesa local, e provavelmente isso assim permanecerá, mas a relação entre o Brasil e o Japão, seja em qualquer área, não pode ser incrementada sem a intermediação da comunidade constituída por imigrantes e seus descendentes. É um ponto curioso observar se, também no Brasil, os aprendizes de língua japonesa se estenderão além do contingente formado pelos descendentes.

Como reverso desse fenômeno, o chamado decasségui, que é impensável no contexto da imigração à América do Norte, pode ser compreendido como um fortalecimento da relação econômica e humana entre o Brasil e o Japão, intermediado pela comunidade de imigrantes. Atualmente, no Japão, existem comunidades onde pode se viver, até certo ponto, falando apenas o português. Mas em muitas situações, ainda se depende dos intérpretes e é possível afirmar que esse grande fluxo de mão-de-obra, denominado decasségui, contribuiu para elevar o valor da língua japonesa como capital cultural. Além disso, aumentou a demanda pelo conhecimento do português no Japão e provocou o consequente aumento dos aprendizes. Os jornais publicados em português (ou em espanhol) no Japão têm desempenhado um papel similar àquele outrora exercido pelos jornais em japonês no Brasil, ou seja, de mídia de língua étnica. Como semelhanças, é possível citar o fato de que nessas 
páginas são publicados artigos sobre o Japão, Brasil e comunidade de decasségui, ou que os anúncios ali encontrados constituem um guia indispensável para tomar decisões da vida cotidiana, sobretudo para aqueles que não lêem o japonês. Obviamente, o incremento dos sites em português e as transmissões de TV a cabo têm alterado o conteúdo das informações exigidas nos jornais.

\section{Lingua da Colônia}

O maior exemplo do contato entre a imigração japonesa e a cultura brasileira pode ser o chamado koroniago, literalmente "linguagem da colônia", assim denominado pelos japoneses da primeira geração, que constitui o emprego do japonês com constante empréstimo das palavras do português. Por exemplo, temos "yowa domingoni operasuru" ou seja, "vou operar no domingo" Consta nos registros que os japoneses da geração Kasato-maru já o empregavam nos primeiros anos da colonização, e podem ser identificadas várias ocorrências no jornal publicado em japonês na primeira década do século passado. Como características do koroniago, podemos citar que dificilmente ultrapassa o nível lexical, embora possa ser eventualmente identificado no nível semântico, na locução, onde podem ser verificados mesclas e empréstimos das palavras do português. Predominam nessas palavras aquelas que descrevem objetos, ações ou estados, assim como as expressões de espanto, que desde cedo foram incorporadas. Isso é bastante comum no contexto do contato linguístico, como se verificam nas línguas de contato que originaram entre inglês e espanhol (Spanglish), holandês e línguas do Caribe (papiamento), inglês do Pacífico (pidgin English), que, como resultado da história de mais de um século, possuem manuais de gramática, ou adquiriram o status de segunda língua oficial. No entanto, o koroniago não deverá durar mais do que uma geração, porque a imigração dos japoneses cessou.

Não se sabe se o japonês é essencialmente uma língua que favorece o empréstimo de outras línguas. Pode-se afirmar, entretanto, ao observar o retrospecto histórico e linguístico do Japão, que a elite japonesa incorporou a escrita e o léxico do chinês ao longo de mais de mil anos e, após a Restauração Meiji (em especial após a Segunda Guerra Mundial), o Japão incorporou por empréstimo as palavras das línguas ocidentais que se referem a conceitos e novidades, a mesma prática observada com o português, o que não é motivo de espanto (note-se que os imigrantes japoneses dos países falantes de inglês ou de espanhol também criaram línguas similares). A questão é: como os camponeses do pré-guerra, que pouco conheciam sequer o empréstimo do inglês, conseguiram incorporar, sem resistência, novas palavras? Seria simplesmente uma decorrência natural do contato com língua diferente? 
Tomoo Handa, autor de Imin no Seikatsu no Rekishi (A história da vida dos imigrantes), recorda que os imigrantes recém-chegados viam com admiração o modo com que os imigrantes já instalados falavam, mesclando habilmente as palavras do português. É uma situação semelhante à dos cavalheiros e damas do Japão pretensamente ocidentalizados que se gabavam da superioridade empregando palavras do inglês ou francês, mesmo para aquelas que existiam em japonês. Não é tão alta a possibilidade de que os imigrantes veteranos fossem fluentes em português somente por empregar várias palavras do português, mas ao menos demonstravam que estavam familiarizados com a cultura local, e isso era motivo de respeito para os recém-chegados, pois pareciam dominar a técnica indispensável para se viver na nova terra.

O motivo pelo qual o empréstimo dificilmente alcançava o nível sintático, extrapolando o lexical, era que a gramática das duas línguas apresentava-se muito diferente. Os imigrantes japoneses esbarraram no obstáculo lingüístico muito mais intransponível do que aquele encontrado pelos imigrantes italianos e espanhóis.

Em muitos casos, koroniago foi considerado uma espécie de dialeto do japonês. Evidentemente, não é equívoco considerá-lo uma língua empregada numa região específica, no caso Brasil, mas por não possuir uma trajetória histórica encontrada, por exemplo, nos dialetos de Kumamoto ou da região Nordeste do Japão, por prescindir de um sistema específico de pronúncia ou de expressividade, e por se restringir apenas no nível de empréstimo lexical, não se trata de um dialeto no sentido comumente empregado. É mais correto considerá-lo uma língua coletiva que fortalece $o$ laço entre os seus membros falantes.

Os japoneses isseis, da primeira geração, consideravam que algumas expressões do português não possuíam equivalentes no japonês. Por exemplo, na década de 60 , quando organizou-se um livro didático de japonês em São Paulo, ocorreu uma discussão em torno da palavra "miiryo" (tômorokoshi $i^{2}$ ). Alguns defendiam o emprego da palavra "tômorokoshi" de acordo com o uso no Japão, e outros do termo "miiryo", conforme o costume brasileiro. Um outro sugeriu uma proposta conciliadora, em que se empregaria "miiryo" na redação escolar, por ser natural, mas que no texto do livro constasse "tômorokoshi". Isso demonstra, na realidade, que a visão japonesa de que o livro didático indica (deve indicar) o uso padrão da língua (houve várias discussões e julgamentos acerca dos textos de livro didático, no Japão) foi seguido pelos imigrantes japoneses. Obviamente, as crianças não aprendem a língua apenas pelo livro, mas os educadores isseis acreditavam na autoridade absoluta dos livros didáticos. Na prática, foi editado um livro didático com vários empréstimos do português, mas esse debate refletia, na realidade, o surgimento de uma classe de intelectuais que se orgulhavam do koroniago, uma língua independente do japonês usado no Japão, e,

2. Milho, em japonês (N.T.). 
por extensão, da legitimidade da cultura da colônia japonesa. Guardadas as proporções, era como se a academia de língua portuguesa de Macau (supondo-se que exista uma entidade assim) se levantasse contra Lisboa. Essa discussão acalorada foi se desvanecendo aos poucos na década de 70 , como consequência da redução da população falante e de aprendizes da língua japonesa.

Outra palavra que os isseis não admitiam abandonar, em detrimento do japonês usado no Japão, era a "enshâda" ( $\left.k u w a^{3}\right)$. Já na década de vinte, os jornais a empregavam com frequência, em contraste com " $k u w a$ ", raramente usado. A quase totalidade dos imigrantes japoneses foi enviada ao campo, e o primeiro utensílio agrícola que lhe foi entregue foi a enxada. Assim como na zona rural do Japão, a manutenção de utensílios agrícolas constituía uma importante atividade nas entresafras e dias de folga, e os imigrantes japoneses também aprenderam a valorizar os utensílios do Brasil. A enxada tornou-se um símbolo sagrado de trabalho, assim como o martelo dos trabalhadores russos, e foi incorporada nas expressões como "enshâdawo suteru", uma metáfora para "abandonar a agricultura", assim como "enshâdadako", que significava uma alteração e endurecimento na pele da palma da mão, conseqüência de longos anos de trabalho no campo. Esse "enshâdadako" era símbolo de aplicação e significava prova de confiança entre os japoneses. "Enshâdashugi" significava a ideologia de considerar a agricultura como base da sociedade e nela encontrar o maior significado da vida. Foi escrito um romance intitulado "Wagahai wa enshâda de $a r u$ "7, uma paródia da obra de Natsume Sôseki". Dessa forma, "enshâda" tornou-se uma palavra intraduzivel para o japonês, que carrega um forte sentimento de coleguismo e de pertencimento à coletividade dos colonos japoneses.

\section{Lingua Tupi}

Ao refletir sobre a visão linguística dos imigrantes japoneses, um nome peculiar deve ser destacado. Trata-se de Rokurô Kôyama (1886-1976), pai da professora aposentada da USP, Geny Wakisaka. Tendo aprendido espanhol no Japão e pretendido emigrar para 0 Peru, ele acabou embarcando, por acaso, no Kasato-maru. Já no bordo deste navio, editou um jornal, feito este que o consagrou como pai do jornalismo em japonês do Brasil. $\mathrm{O}$

\section{Enxada, em japonês (N.T.).}

4. Literalmente, "largar a enxada" (N.T.).

5. Literalmente, "calo de enxada" (N.T.).

6. Literalmente, "enxadismo" (N.T.).

7. Na tradução literal, "Eu sou uma enxada". Verifique a semelhança com o título da obra original, na nota 8 (N.T.).

8. Escritor japonês (1867-1916), autor de "Wagahai wa neko dearu" ("Eu sou um gato") (N.T.). 
jornal Seishû Shinpô, editado por Kôyama de 1921 a 1941, período em que as publicações em japonês foram proibidas no Brasil, é conhecido pela riqueza em que retratava as notícias do interior e pelo forte laço estabelecido com os leitores. Após a guerra, enfermo de visão, Kôyama teve que abandonar o jornalismo. Dedicou-se, então, a haiku ${ }^{9}$ e $t a n k a^{10}$, publicando uma antologia, em co-autoria.

Segundo sua autobiografia, um dia após o desembarque no porto de Santos, dentro do trem que seguia rumo a São Paulo, ouviu de Sadajirô Suzuki, um intérprete que já vivia há dois anos nas terras tapuias, o relato de que existiam, neste país, indígenas muito semelhantes aos japoneses. Este fato impressionou-o, aguçando sua curiosidade. Tudo indica que Kôyama passou a interessar pela cultura indígena a partir da década de 1920 , quando já se encontrava estabilizado no Brasil. Consta na sua autobiografia o relato de que sua filha, Geny, ao comentar a figura do imperador Jinmu ${ }^{11}$ que ilustrava um jornal recém enviado do Japão, dissera que "parecia um bugre" Como se verifica posteriormente, essa colocação antecipava sua tese de que os japoneses e tupis possuem ancestral comum.

Kôyama imaginou que se a fisionomia dos japoneses e tupis é semelhante, suas línguas também devem o ser, e, de forma arrojada, considerou que ambos possuem o mesmo ancestral na Polinésia e que teriam emigrado na antiguidade remota, um para o norte e outro para o leste do Pacífico. Obviamente, do ponto de vista dos linguistas e dos antropólogos acadêmicos, essa tese não passa de uma suposição prosaica e absurda. Entretanto, não é uma tarefa inútil verificar a base histórico-cultural dessa fantasia. A origem da língua e a língua universal constituem os temas que foram descartados da atuação da Linguística, no momento da sua consolidação nas universidades européias, no século XIX, mas os lingüistas diletantes debruçaram sobre eles com apego e apresentaram hipóteses originais. O lingüista francês Sylvain Auroux, por exemplo, ao seguir a genealogia da glossomania, em La Linguistique Fantastique (Paris, 1985), realiza um estudo crítico da cientificidade da Linguística, tratando das fronteiras do conhecimento que a mesma, como Ciência propriamente dita, não consegue enfrentar. Pode-se afirmar que a tese de Kôyama, de ancestral comum dos japoneses e tupis, pertence à mesma categoria de Linguistique Fantastique.

Após realizar pesquisas sobre a língua tupi, Kôyama publicou um pequeno dicionário japonês-tupi, intitulado Tupigo Tangosh $\hat{u}^{12}$ (1951). A bibliografia em português serviu como base para a comparação realizada entre essas duas línguas. Mas, diferentemente dos dicionários de português e de tupi publicados nos séculos XVIII e XIX, quando havia

9. Poema tradicional japonês, composto por dezessete sílabas, conhecido como haicai (N.T.).

10. Também poema tradicional, composto por trinta e uma sílabas (N.T.).

11. Ser mitológico, considerado primeiro imperador do Japão (N.T.).

12. "Coletânea de termos tupi" (N.T.). 
uma necessidade prática para o seu uso, o dicionário de Kôyama era para apenas ser lido na escrivaninha, uma vez que não havia oportunidade para os falantes de japonês e de tupi se comunicarem.

Entretanto, o que mais chamou atenção de Kôyama foi o fato de que havia muitas palavras indígenas entre as toponímias editadas. Como afirmou Teodoro Sampaio, paulista e pensador nacionalista, em O tupi na Geographia Nacional (Bahia, 1928), indicado na bibliografia de Kôyama, descobrir o significado das toponímias em língua tupi intensificava o apego à terra. E, por conseguinte, intensificava o apego ao Brasil. É um raciocínio comumente verificado no nacionalismo brasileiro da primeira metade do século $\mathrm{XX}$, que tinha como necessidade explicitar a diferença do Brasil e a civilização européia. Por meio das pesquisas de língua tupi, Sampaio tentou resgatar o significado original da terra, que caíra em esquecimento. Posicionando-se como um dos homens civilizados, tentou elaborar a longa história brasileira pré-Cabral, destacando partes da cultura dos povos primitivos que foram dizimados. $O$ ato de registrar as línguas ágrafas com o sistema de escrita europeu significava dominar e tomar posse, linguisticamente, das terras dos primitivos. Os pesquisadores de tupi brasileiros utilizaram a figura dos povos autóctones, quase todos extintos, como uma amálgama ideológica invisivel para construir a concepção do Brasil multirracial. Foi uma condição necessária para concretizar a ideologia do povo brasileiro constituído por três raças (européia, africana e americana), mas as línguas dos povos que na prática desapareceram deixaram vestígios nas toponímias, no léxico, no sotaque e nas cerimônias cristãs do interior do país. Nesse contexto, o povo tupi é louvado, de forma ilusória, como povo nacional.

Em contraposição, Kôyama resgatou o povo tupi para reconhecer os japoneses, do ponto de vista histórico e racial, como constituinte tradicional e legítimo do povo brasileiro. Ou seja, se os tupis são membros legítimos do povo brasileiro, seus irmãos japoneses também devem o ser. Já que a sua fisionomia é parecida, a língua também deve apresentar semelhanças. Assim, supôs, ou melhor, desejou. No tupi, há muitas palavras compostas, como "itaca" (caverna), resultante de "ita" (pedra) e "ca" (casa). Observando esse fato, Kôyama interpretou que os tupis representavam pelo som dos elementos básicos da natureza aquilo que é considerado hen ${ }^{13}$ do kanji do japonês. O kanji constitui um dos três subsistemas de escrita do japonês, criado na China e representa, principalmente, os conceitos complexos. De um modo geral, é formado por agrupamento de múltiplos componentes básicos, sendo um deles o hen, que expressa pedra, peixe, grama etc., tendo como origem os pictogramas (por exemplo, o sakanahen originou-se do desenho de um peixe).

13. Radical, uma das partes que constituem o kanji (N.T.). 
Kôyama não apresentava apego doentio à sistematização, comum entre os lingüistas aficionados, e esperava que os leitores de Tupigo Tangosh $\hat{u}$ apreciassem seu "encantamento poético" e "senso de humor" O estabelecimento de vínculo entre o tupi e o kanji talvez deva ser interpretado como uma faceta desse desejo. Mas do ponto de vista lingüístico, era um salto que relacionava uma língua ágrafa a um sistema de escrita do outro lado do planeta. Kôyama parece querer afirmar que os dois povos, a despeito da diferença de localização e de língua, apreendiam o mundo de forma semelhante. Ele interpretava que o fato de algumas palavras tupis serem semelhantes às toponímias e substantivos do japonês servia implicitamente como comprovação de sua tese.

Após a publicação de Tupigo Tangosh û, Kôyama concentrou-se em comprovar a relação familiar entre as línguas, o que considerava análoga à semelhança fisionômica. Os resultados dessa busca foram publicados em 1970 e 1973. Nesses trabalhos, Kôyama procura, em primeiro lugar, relacionar, à força, as sílabas do japonês com os significados do tupi. Isso se faz atribuindo vários significados a uma sílaba, no processo de tradução dupla: tupi para o português e este para o japonês. No japonês, pelo fato de utilizar o kanji, uma sílaba costuma ter vários significados, e Kôyama explora essa possibilidade ao máximo. Em seguida, ele trata dos casos de duas sílabas, de três sílabas, e, por fim, defende a tese de que todas as línguas do mundo se originaram do tupi. Pode parecer uma tolice do ponto de vista da Linguística, mas para Kôyama, esse fato justificava que o tupi seria a língua primeva do mundo. Sendo assim, o japonês, língua-irmã, também fazia parte da linhagem nobre.

Por que Kôyama insistiu tanto que os japoneses e tupis tivessem um ancestral comum? No Japão, a origem dos japoneses é um assunto que desperta muita atenção. Nessa extensão, a origem da língua japonesa também acarreta discussões e especulações de todas as estirpes, inclusive com hipóteses de leigos que fazem analogia pela semelhança das palavras. Uma publicação recente verifica minuciosamente as semelhanças entre o japonês e o latim.

Em todo caso, a discussão sobre a origem do japonês não contribui para explicar a origem dos brasileiros nikkeis. Na prática, o Kasato-maru simboliza a origem, mas assim como as embarcações de Cabral, não se trata de origem do povo. E o mito fundante do Brasil, de três raças, não inclui os asiáticos. Então, um artifício empregado por Kôyama foi relacionar os indígenas e os japoneses a um ancestral comum. Nessa ótica, os povos irmãos dos japoneses já haviam aportado no Brasil, antes dos europeus que depois constituiram a civilização brasileira. Tanto os tupis quanto os nikkeis estão na margem da sociedade brasileira. Mas, na realidade, nós é que estamos na origem da história do Brasil. Assim pensou esse imigrante intelectual, que, fazendo uso de sua fantasia lingüística, tentou resolver o incômodo de ser, ao mesmo tempo, cidadão e minoria étnica (em detalhes, cf. Hosokawa, S. Tôkini arite tsukurumono - Nikkei burajirujinno omoi, kotoba, geinô. Tóquio: Misuzushobô, 2008). 
Verificamos, até aqui, os casos de contato cultural dos isseis. Relatei, sobretudo sobre os casos relacionados com a língua japonesa. A partir de agora, pretendo tratar dos casos de contato cultural dos nisseis e sanseis. Realizei, na primeira metade da década de 1990, um levantamento sobre o karaokê no Brasil, e conferi muitas crianças que não falam japonês cantarem as músicas japonesas, e recentemente essas músicas estão sendo traduzidas para o português, como por exemplo, "Kanpai" O grupo de taiko ${ }^{14}$ que, nessa época, só havia um em São Paulo, passou a ter quatro ou cinco, inclusive na escola de língua japonesa. $\mathrm{Na}$ mesma época, ocorreu um aumento vertiginoso desses grupos de taiko na América do Norte e no Havaí, expandindo-se para Austrália e Europa, inclusive para os vários países da América do Sul. Atualmente, espalham-se grupos de taiko organizados pelos descendentes, com inclusão de demais participantes, nos países como Peru, Paraguai e Bolívia. Vários aspectos importantes podem ser revelados através da pesquisa sobre os grupos de taiko, como os fundadores, líderes, aquisição de instrumentos, locais de apresentação, motivação dos participantes, realidade dos ensaios, reação do público etc. Nos quesitos disciplina e educação, ou no aspecto corpóreo genuinamente oriental, podemos identificar um grande ponto de convergência com o sucesso que as lutas marciais japonesas auferem.

No agosto deste ano, assisti às apresentações de Ryukyûkoku Taiko e outros quatro grupos de taiko da linha de Okinawa ${ }^{15}$, na Comemoração do Centenário da Imigração Okinawana no Brasil. Foi um grande espetáculo em que centenas de componentes tocavam vestidos de traje típico, hasteando pendões, com coreografias sincronizadas, sob forte iluminação. Com a exceção do taiko, toda a orquestra era gravada, e evidentemente não havia nenhum significado de culto aos antepassados, como existia originalmente. Havia visto uma apresentação similar há três anos, no Peru, onde os descendentes de okinawanos ocupam metade dos imigrantes japoneses. Em Okinawa, a partir da década de 90, os shows de apresentação de taiko começaram a ser realizados pelos jovens no encerramento dos eventos, e vem se intensificando anualmente. A partir dos anos 80, a cultura de Okinawa passou a ser valorizada na ilha principal do Japão, começando pela apresentação de um grupo de rock de Okinawa, tendo como inspiração o Eisâ (bom-odori ${ }^{16}$ ), para uma platéia formada por milhares de pessoas. Desde então, tendo esse evento como um dos marcos, iniciou um movimento de transformar o tradicional Eisâ para um espetáculo. E pode se

14. Tambor, geralmente tocado em grupos (N.T.).

15. Ilha do extremo sul do Japão (N.T.).

16. Dança folclórica que inicialmente era apresentada na época de finados, com o propósito de cultuar o espírito dos antepassados (N.T.). 
afirmar que esse movimento chegou ao Novo Continente. $O$ apoio entusiasmado da provincia de Okinawa tem possibilitado a expansão desses movimentos.

A espetaculização do Eisâ no Okinawa corresponde ao boom do Yosakoi Sôran verificado na ilha principal. Originalmente, não havia nenhuma relação entre Yosakoi de Kôchi e Sôran de Hokkaido, nem eram dançados nas ruas do bairro. Eram as gueixas que dançavam nesses ritmos nas zonas de tolerância, e esse gênero conhecido como min yô era tido como antiquado e rejeitado pelos jovens. A grande virada veio na década de 1980 com um cantor de min'yô que passou a apresentar tendo como acompanhamento o rock. No início, destacava-se pela originalidade, mas aos poucos esse min'yô com estilo de rock foi conquistando fãs, ao contrário de min 'yô tradicional que é acompanhado por instrumentos japoneses, cujos cantores e apreciadores envelheciam. Nos anos 90, como uma das medidas de revitalização das cidades regionais, foram realizados festivais em que jovens locais começaram a dançar o Sôran e Yosakoi no ritmo de rock. A coreografia tornou-se dinâmica, incorporando o ritmo do rock. Esse evento impulsionou o novo estilo, que alguns anos depois viram fundir os dois ritmos e o aumento da espetaculização. Empregando-se guitarras eletrônicas e amplificadores, e adaptando-se à tendência mundial, misturando os componentes étnicos. A escala desses eventos faz lembrar as festas de São João do nordeste brasileiro. E no início do século XXI, foi importado para o Brasil.

No contexto do Japão, a espetaculização e a descoberta de Yosakoi e Eisâ representaram o resgate da tradição e confiança sobre a própria cultura. Talvez isso possa ser relacionado com o fato de que, já no século XXI, as escolas de ensino básico japonesas terem incorporado os instrumentos musicais tradicionais na disciplina obrigatória de música, e os jovens passaram a ter mais familiaridade com taiko e shamisen ${ }^{17}$ do que na fase anterior. Mais do que isso, talvez a ampliação da chamada "sociedade do espetáculo" tenha incentivado o aumento dos espetáculos de cunho folclórico e étnico. $\mathrm{Na}$ "sociedade do espetáculo" a mídia, a indústria do entretenimento e os governos locais se unem para promover grandes festivais e eventos que agregam emoções, sentimentos e organismos da população, visando ao fortalecimento do sentimento de união dos citadinos e ainda da consciência étnica. Vale lembrar que, no Japão, desde muito tempo, tudo é concentrado no centro do país e o esvaziamento do interior tem sido um problema. Por isso, os governos locais, sem exceção, têm se esforçado para estancar a emigração, planejando diversas formas de revitalização das vilas do interior, tomandoas atraentes à população. Combinando os interesses dos governantes e o entusiasmo dos praticantes, Yosakoisôran e Eisâ foram se expandindo para o restante do país.

Quando foram introduzidas no Brasil, essas performances correspondiam ao advento do multietnicismo que valorizavam as peculiaridades dos imigrantes minoritários. Para os

17. Instrumento musical tradicional, de três cordas (N.T.). 
participantes nisseis e sanseis, trata-se de uma oportunidade de aprender sobre os trajes que combinam com sua aparência, representação e música, e ainda tem sido conveniente para estreitar os laços internos de membros da mesma geração do grupo étnico minoritário. Para os membros não-descendentes de japoneses, isso atrai por representar traços exóticos do estrangeiro, uma alternativa cultural diferente da genuinamente brasileira ou "internacional", anglo-saxônica. Para as associações de japoneses, que organizam as festividades, trata-se de uma oportunidade para mostrar a sua presença, distinguindo-se de outros grupos étnicos da sociedade. Atualmente, essas performances não diferem daquelas desenvolvidas no Japão ou no Peru, mas na próxima geração podem aumentar traços brasileiros mais fortes. Isto porque a convergência de várias culturas é a característica do Brasil.

Citando outro exemplo, temos o caso de Matsuri Dance do grupo Isshin, formado pelos jovens nikkeis de Maringá, Paraná, cuja apresentação tive oportunidade de presenciar no ano passado, na entidade Ikoi no Sono de Guarulhos. Vestindo quimono (por baixo, camiseta e calça jeans) e com faixa amarrada na cabeça, os jovens dançam no ritmo J-pop formando círculo, e a coreografia combina bon-odori, ritmo de discoteca e o estilo semelhante com ginástica, denominado para-para no Japão. Repetindo os movimentos de avanço e recuo típicos de bon-odori, acompanha o ritmo movimentando o quadril, dá um salto após girar, e bate palmas. Nas reuniões dos japoneses, são inerentes à dança Tóquioondo e Tankôbushi, executadas pelo departamento de senhoras, mas não conseguem romper as barreiras de idade, sexo e etnicidade. Diferentemente dessas danças, o Matsuri Dance tem sua música e movimentos originários na cultura pop, e por isso tem adesão animada dos não-descendentes e crianças.

Esse estilo não foi transmitido pelos isseis, mas deve ter sido elaborado coletivamente a partir do mangá, animê, $\mathrm{CD}$ e internet. Por falar em dançar em círculo, isso faz recordar o "Takenoko-zoku", na década de 80, em que jovens dançavam com trajes arrojados, aos domingos, no parque Yoyogi e calçada das ruas, mas não consigo estabelecer relação entre eles. Talvez algum ex-decasségui tenha dado uma dica. Parece que teve início em 2000, no Estado do Paraná, e ouvi dizer que conseguem mobilizar 10 mil pessoas. Um educador que veio do Japão considerou tratar-se de uma distorção da cultura japonesa, mas senti no rosto dos dançarinos uma expressão de criação cultural em curso. Uma cultura à japonesa que não é transmitida pela língua ou relação de parentesco, mas pelos novos recursos midiáticos, e que é remodelada de acordo com a imaginação sobre o Japão e as particularidades locais. Isso faz lembrar o sucesso de sushi Califórnia e cosplay. Trata-se de uma reinterpretação da cultura japonesa em escala mundial, e no Brasil, os jovens que carregam o sangue nipônico têm sido protagonistas da adaptação da dança dos pais e avós para o estilo próprio.

Pode-se afirmar que Matsuri Dance é o bon-odori dos dias de hoje. Lembro que antes da Segunda Guerra, no carnaval do salão de dança japonês, os idosos, sem 
familiaridade com samba, dançavam o bon-odori. Atualmente, seus netos ensinam, com orgulho, os passos dessa dança para os brasileiros. Na apresentação de taiko dos alunos do ensino básico que presenciei no Ikoi no Sono, detectei o ritmo de samba incorporado. Será que se tornarão semelhantes ao Olodum Mirim, grupo de batucada das crianças afrobrasileiras da Bahia?

\section{Conclusões}

Como inicialmente mencionado, a imigração é uma decorrência da modernização do Japão e sua cultura e história devem ser pesquisadas cada vez mais. O Brasil possui a maior comunidade de japoneses do mundo e a cultura japonesa está presente sob diversas formas. Para se estudar essa incorporação e adaptação, é necessário conhecer a forma original no Japão. Sendo que o Japão muda a sua imagem de acordo com o ângulo pelo qual é examinado e enquanto a definição de cultura apresenta variações infinitas, tentar caracterizar a cultura japonesa com poucas palavras é atentar contra os princípios das Ciências Humanas. Justamente por não poder resumir em poucas palavras é que inúmeras interpretações e análises contraditórias entre si foram apresentadas até agora. Enquanto não se estabelecer do qual Japão está se discutindo, só obteremos conclusões superficiais e simplistas. Da mesma forma, a cultura se refere à totalidade da vida e modo de pensar das pessoas e não é possível retalhá-la em partes.

Pesquisar a cultura japonesa no Brasil acarreta conhecer profundamente a existência dos imigrantes neste país e, como conseqüência, implica conhecer a cultura brasileira. Certamente, a cultura japonesa tem se tornado, lentamente, $e$ às vezes de forma brusca, uma parte da cultura brasileira. Este Simpósio tem como finalidade confirmar a atualidade desse processo no nível do conhecimento e promover a continuidade dessa abordagem. Queremos constituir um patrimônio que possa ser compartilhado pelos pesquisadores e estudantes de ambos os países.

(Tradução e notas de Wataru Kikuchi) 